\title{
Nonspecific Symbiosis Between Sophora flavescens and Different Rhizobia
}

\author{
Yuan Hui Liu, ${ }^{1}$ Yin Shan Jiao, ${ }^{1}$ Li Xue Liu, ${ }^{1}$ Dan Wang, ${ }^{1}$ Chang Fu Tian, ${ }^{1}$ En Tao Wang, ${ }^{1,2}$ Lei Wang, ${ }^{1}$ \\ Wen Xin Chen, ${ }^{1}$ Shang Ying Wu, ${ }^{3}$ Bao Lin Guo, ${ }^{4}$ Zha Gen Guan, ${ }^{5}$ Véréna Poinsot, ${ }^{6}$ and Wen Feng Chen ${ }^{1, \dagger}$ \\ ${ }^{1}$ State Key Laboratory of Agrobiotechnology; College of Biological Sciences and Rhizobium Research Center, China Agricultural \\ University, Beijing 100193, China; ${ }^{2}$ Departamento de Microbiología, Escuela Nacional de Ciencias Biológicas, Instituto \\ Politécnico Nacional, México D. F. 11340, México; ${ }^{3}$ Changzhi County Agriculture Committee, Changzhi County Welcome West \\ Street. No. 6, Shanxi Province 046000, China; ${ }^{4}$ Institute of Medicinal Plant Development, Chinese Academy of Medical \\ Sciences and Peking Union Medical College, Beijing 100193, China; ${ }^{5}$ Shanxi Zhendong Pharmaceutical Co., Ltd. Changzhi, \\ Shanxi Province 047100, China; ${ }^{6}$ Laboratoire des IMRCP, UMR5623 Université Paul Sabatier, Toulouse, France
}

Accepted 18 September 2017.

\begin{abstract}
We explored the genetic basis of the promiscuous symbiosis of Sophora flavescens with diverse rhizobia. To determine the impact of Nod factors (NFs) on the symbiosis of S. flavescens, nodulation-related gene mutants of representative rhizobial strains were generated. Strains with mutations in common nodulation genes (nodC, nodM, and nodE) failed to nodulate S. flavescens, indicating that the promiscuous nodulation of this plant is strictly dependent on the basic NF structure. Mutations of the NF decoration genes $\operatorname{nodH}, \operatorname{nod} S, \operatorname{nodZ}$, and noeI did not affect the nodulation of $S$. flavescens, but these mutations affected the nitrogen-fixation efficiency of nodules. Wild-type Bradyrhizobium diazoefficiens USDA110 cannot nodulate $S$. flavescens, but we obtained $14 \mathrm{Tn} 5$ mutants of $B$. diazoefficiens that nodulated $S$. flavescens. This suggested that the mutations had disrupted a negative regulator that prevents nodulation of $S$. flavescens, leading to nonspecific nodulation. For Ensifer fredii CCBAU 45436 mutants, the minimal NF structure was sufficient for nodulation of soybean and $S$. flavescens. In summary, the mechanism of promiscuous symbiosis of $S$. flavescens with rhizobia might be related to its nonspecific recognition of NF structures, and the host specificity of rhizobia may also be controlled by currently unknown nodulation-related genes.
\end{abstract}

As nitrogen-fixing microsymbionts associated with leguminous plants, rhizobia or root and stem nodule bacteria have been extensively studied for more than 100 years. Although many studies have focused on their genetic, genomic, biochemical, and biophysical characteristics (diCenzo et al. 2016; Long 2001; Marx et al. 2016; Tian et al. 2012), some details of the interactions between rhizobia and their host legumes remain unclear. This is mainly because of the shortage of host plant backgrounds and the complexity of interactions among the symbiotic partners and environmental factors. Some host plants can be nodulated by a diverse range of rhizobia while others have a narrower range of symbiotic partners. For example, all the rhizobial strains nodulating alfalfa

\footnotetext{
${ }^{\dagger}$ Corresponding author: Wen Feng Chen; E-mail: chenwf@cau.edu.cn
}

*The $\boldsymbol{e}$-Xtra logo stands for "electronic extra" and indicates that seven supplementary figures and two supplementary tables are published online.

○ 2018 The American Phytopathological Society isolated to date belong to Ensifer meliloti (formerly Sinorhizobium meliloti), even in diverse geographical regions (Stajković-Srbinović et al. 2012). Common bean (Phaseolus vulgaris) is nodulated by different rhizobial species harboring similar nodulation genes in different regions (Wang et al. 2016), while soybean (Glycine max) is nodulated by distinct rhizobial species harboring diverse nodulation genes (Tian et al. 2012; Zhang et al. 2011). These variations in the rhizobial spectrum for different host legumes are related to interactions among the host legumes, the symbiotic bacteria, and their genes (the combination of chromosome background and symbiotic genes) and environmental factors (Wang et al. 2016; Zhang et al. 2011), but the exact mechanisms of such interactions are still unknown. To explore these relationships, model systems of symbiotic legumes with a narrow rhizobial spectrum and those with promiscuous rhizobial relationships are very important for detailed comparative analyses.

The specificity between legume hosts and their compatible rhizobia is determined by a molecular dialog. That is, the roots of the legume release flavonoids that are recognized by rhizobia and induce the synthesis of Nod factors (NFs). The host recognizes the NFs produced by rhizobia, and this initiates the infection and nodule-formation process (Long 1996). The essential chemical structure of NFs comprises lipochitooligosaccharides (LCOs), which are monoacylated oligomers of three to six $\beta-1,4-$ linked $N$-acetyl-D-glucosamine (GlcNAc) units. Biosynthesis of the LCOs in rhizobia depends on the products of nodulation genes (nod, noe, nol) that are specifically induced by flavonoids secreted by the legume hosts. Several nodulation genes are common to all rhizobia, including nodA (encoding $N$-acyltransferase), $n o d B$ (encoding deacetylase), and $\operatorname{nod} C$ (encoding $N$-acetylglucosaminyltransferase). The only exceptions are the photosynthetic Bradyrhizobium strains BTAi1 and ORS278, in which the canonical nodABC genes and a typical NF are not required for symbiosis with some legumes (Giraud et al. 2007). Together, nodABC genes manufacture the LCO chitin backbone, while hostspecific nodulation genes specific to each rhizobial strain are responsible for structural modifications of the chitin backbone at both the reducing and nonreducing ends. For example, nodS and noeI are responsible for methylation, nodZ for fucosylation, nodH for sulfation, nodL for acetylation, and nod $U$ for carbamylation (Day et al. 2000). These structural variations are responsible for the host-specificity of some rhizobial strains. Previous studies have shown that mutations affecting nodABC genes totally block nodulation, whereas mutations in other nod genes cause a variety of phenotypes, including delayed nodulation, reduced number of nodules, altered host specificity, or no visible effect (Long 1989). 
The legume Sophora flavescens has been defined as an extremely promiscuous host for rhizobia because it can establish symbioses with diverse rhizobia harboring different types of nodC genes (Jiao et al. 2015). However, whether rhizobia without common nod genes can nodulate this plant and how specific nod genes in rhizobia function in nodulating this promiscuous host remained unclear. In addition, both Bradyrhizobium diazoefficiens and Ensifer fredii (formerly Sinorhizobium fredii) are known to effectively nodulate soybean, but only $E$. fredii can nodulate $S$. flavescens. Therefore, this fact suggests that these two rhizobial species may differ in selecting their respective host ranges besides their common host, soybean.

To address these unknowns and to explore the molecular basis of the promiscuous nature of $S$. flavescens, we conducted this study with six rhizobial species (four genera) belonging to four different cross-nodulation groups. Three common nodulation genes (nodC as well as $\operatorname{nodE}$ and $\operatorname{nod} M$, encoding $\beta$-ketoacyl synthase [Demont et al. 1993] and D-glucosamine synthase [Baev et al. 1992], respectively) and four LCO-modification genes (nodS, noel, nodZ, and $\operatorname{nod} H$ ) (Supplementary Fig. S1) were mutated in selected rhizobial strains to evaluate their relevance in the interaction with $S$. flavescens. As a result, we determined the minimal nodulation gene unit and the basic LCO structure of $E$. fredii CCBAU45436 required for nodulation of $S$. flavescens. A Tn5 mutant library of $B$. diazoefficiens USDA110 was produced, and the ability of insertion mutants to nodulate S. flavescens was evaluated. The results of these analyses shed light on the basic requirements for nodulation with this promiscuous legume.

\section{RESULTS}

\section{Ability of selected rhizobial strains \\ to nodulate $S$. flavescens.}

The six wild-type (WT) rhizobial strains (Table 1) were $E$. fredii and $B$. diazoefficiens isolated from soybean, Rhizobium yanglingense and Mesorhizobium amorphae isolated from Caragana intermedia, Rhizobium etli isolated from Phaseolus vulgaris, and Mesorhizobium huakuii isolated from Astragalus sinicus. Each strain formed effective root nodules on their host of origin and no cross-nodulation was observed among these strains isolated from different host plants. All strains except $B$. diazoefficiens formed functional nodules on S. flavescens (Tables 2 and 3). Therefore, these strains were suitable for the subsequent analyses.

\section{Nodulation by mutants of common nod genes.}

This analysis was performed to test the role of NFs in the promiscuous nodulation of $S$. flavescens. First, the nod $C$ gene was successfully deleted from all the tested rhizobial strains. None of the $\operatorname{nodC}$-deletion mutants was able to nodulate $S$. flavescens or their original hosts (Table 2; Supplementary Table S1). The shoot dry weight and leaf chlorophyll concentrations were significantly lower in plants inoculated with nodC-mutant strains than in those inoculated with WT strains (Table 2). Similarly, the nodE or nodM mutant of $E$. fredii, the nodE mutant of $R$. yanglingense, and the nod $M$ mutant of $M$. amorphae were defective in nodulating their original hosts (G. max, C. intermedia) and S. flavescens (Table 2). Accordingly, the leaf chlorophyll content and shoot dry weights were significantly higher in plants inoculated with the three WT strains than in those inoculated with the common nod-gene (nodE and $\operatorname{nod} M$ ) mutant strains (Table 2).

\section{Nodulation by mutants of specific nod genes.}

To test if genes involved in LCO decoration affected the promiscuous nodulation of $S$. flavescens, four nod genes (nodS, noel, nodZ, and nod $H$ ) were deleted or mutated in various rhizobial strains (Tables 1 and 3). Except for strain USDA110, all the mutants of LCO-decoration genes effectively nodulated S. flavescens and their original hosts (Table 3). Leaf chlorophyll content, number of nodules, and fresh weight of nodules did not differ significantly between $S$. flavescens plants inoculated with

Table 1. Strains and plasmids used in this study

\begin{tabular}{|c|c|c|}
\hline Strains or plasmids & Relevant characteristics & Source or reference \\
\hline \multicolumn{3}{|l|}{ Strains } \\
\hline Ensifer fredii CCBAU $45436 \mathrm{WT}$ & Wild-type isolate from root nodule of Glycine $\max$ & Zhang et al. 2011 \\
\hline$\Delta$ nodC & nodC deletion mutant, $\mathrm{NA}^{\mathrm{r}}, \mathrm{Tmp}^{\mathrm{r}}, \mathrm{Gm}^{\mathrm{r}}$ & This study \\
\hline$\Delta$ nodE & nodE deletion mutant, $\mathrm{NA}^{\mathrm{r}}, \mathrm{Gm}^{\mathrm{r}}$ & This study \\
\hline$\Delta$ nodM & nodM deletion mutant, $\mathrm{NA}^{\mathrm{r}}, \mathrm{Gm}^{\mathrm{r}}$ & This study \\
\hline$\Delta$ nodS & nod $S$ deletion mutant, $\mathrm{NA}^{\mathrm{r}}, \mathrm{Tmp}^{\mathrm{r}}, \mathrm{Gm}^{\mathrm{r}}$ & This study \\
\hline SnoeI & pVO155::noeI insertion mutant, $\mathrm{NA}^{\mathrm{r}}, \mathrm{Tmp}^{\mathrm{r}}, \mathrm{Km}^{\mathrm{r}}$ & This study \\
\hline 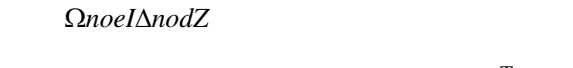 & $\begin{array}{l}\text { nodZ deletion and noel insertion double mutant, } \mathrm{NA}^{\mathrm{r}}, \mathrm{Tmp}^{\mathrm{r}} \text {, } \\
\mathrm{Gm}^{\mathrm{r}}, \mathrm{Km}^{\mathrm{r}}\end{array}$ & This study \\
\hline Bradyrhizobium diazoefficiens USDA $110^{\mathrm{T}} \mathrm{WT}$ & Wild-type isolate from root nodule of Glycine $\max , \mathrm{Tmp}^{\mathrm{r}}, \mathrm{Amp}^{\mathrm{r}}$ & Delamuta et al. 2013 \\
\hline SnoeI & pVO155::noel insertion mutant, $\mathrm{NA}^{\mathrm{r}}, \mathrm{Tmp}^{\mathrm{r}}, \mathrm{Km}^{\mathrm{r}}$ & This study \\
\hline Rhizobium yanglingense CCBAU $01603 \mathrm{WT}$ & Wild-type isolate from root nodule of Caragana intermedia & Li et al. 2012 \\
\hline$\Delta n o d C$ & nodC deletion mutant, $\mathrm{NA}^{\mathrm{r}}, \mathrm{Gm}^{\mathrm{r}}$ & This study \\
\hline$\Delta n o d E$ & nodE deletion mutant, $\mathrm{NA}^{\mathrm{r}}, \mathrm{Gm}^{\mathrm{r}}$ & This study \\
\hline Mesorhizobium amorphae CCBAU 01583 WT & Wild-type isolate from root nodule of Caragana intermedia & Li et al. 2012 \\
\hline$\Delta$ nodC & nodC deletion mutant, $\mathrm{NA}^{\mathrm{r}}, \mathrm{Gm}^{\mathrm{r}}$ & This study \\
\hline$\Delta$ nodM & nodM deletion mutant, $\mathrm{NA}^{\mathrm{r}}, \mathrm{Gm}^{\mathrm{r}}$ & This study \\
\hline R. etli CFN42 ${ }^{\mathrm{T}} \mathrm{WT}$ & Wild-type isolate from root nodule of Phaseolus vulgaris & Segovia et al. 1993 \\
\hline$\Delta$ nodC & nodC deletion mutant, $\mathrm{NA}^{\mathrm{r}}, \mathrm{Tmp}^{\mathrm{r}}, \mathrm{Gm}^{\mathrm{r}}$ & This study \\
\hline$\Delta$ nodS & nod $S$ deletion mutant, $\mathrm{NA}^{\mathrm{r}}, \mathrm{Tmp}^{\mathrm{r}}, \mathrm{Gm}^{\mathrm{r}}$ & This study \\
\hline M. huakuii 7653R WT & Wild-type isolate from root nodule of Astragalus sinicus & Wang et al. 2014 \\
\hline$\Delta$ nodC & nodC deletion mutant, $\mathrm{NA}^{\mathrm{r}}, \mathrm{Tmp}^{\mathrm{r}}, \mathrm{Gm}^{\mathrm{r}}$ & This study \\
\hline$\Delta n o d H$ & nodH deletion mutant, $\mathrm{NA}^{\mathrm{r}}, \mathrm{Tmp}^{\mathrm{r}}, \mathrm{Gm}^{\mathrm{r}}$ & This study \\
\hline Escherichia coli $\mathrm{DH} 5 \alpha$ & Competent cell & \\
\hline \multicolumn{3}{|l|}{ Plasmids } \\
\hline pCM351 & Plasmid for homologous double-crossover, $\mathrm{Gm}^{\mathrm{r}}, \mathrm{Tet}^{\mathrm{r}}$ & Marx and Lidstrom 2002 \\
\hline pCM184 & Plasmid for insertion mutation, $\mathrm{Km}^{\mathrm{r}}$ & Marx and Lidstrom 2002 \\
\hline pRK2013 & Helper plasmid for triparental conjugation, $\mathrm{Km}^{\mathrm{r}}$ & Figurski and Helinski 1979 \\
\hline pRL1063a & Plasmid bearing $\mathrm{Tn} 5$ derivative $\mathrm{Tn} 5-1063, \mathrm{Km}^{\mathrm{r}}, \mathrm{Bm}^{\mathrm{r}}, \mathrm{Sm}^{\mathrm{r}}$ & Wolk et al. 1991 \\
\hline pVO155 & Whole-genome insertion mutagenesis, $\mathrm{Km}^{\mathrm{r}}$, $\mathrm{Amp}^{\mathrm{r}}$ & Oke and Long 1999 \\
\hline
\end{tabular}

${ }^{\mathrm{a}} \mathrm{WT}=$ wild type, $\mathrm{NA}=$ nalidixic acid, $\mathrm{Tmp}=$ trimethoprim $=\mathrm{Km}=$ kanamycin, $\mathrm{Gm}=$ gentamicin, Tet $=$ tetracycline, $\mathrm{Bm}=$ bleomycin, $\mathrm{Sm}=$ streptomycin, Amp $=$ ampicillin, ${ }^{\mathrm{r}}=$ resistance. 
WT and those inoculated with $E$. fredii and $R$. etli nodS mutant strains (Table 3). However, the dry weight was significantly lower in $S$. flavescens plants inoculated with these two nodS mutants than in those inoculated with WT. The nodulation phenotype of the original host, $P$. vulgaris, showed no significant difference between those inoculated with the R. etli nodS mutant and those inoculated with the WT strain. In soybean, the leaf chlorophyll content and shoot dry weight were significantly lower, while the number and fresh weight of nodules were significantly higher, in plants inoculated with the $E$. fredii nodS mutant than

Table 2. Nodulation phenotype of common nod gene mutants on Sophora flavescens and original hosts ${ }^{\mathrm{a}}$

\begin{tabular}{|c|c|c|c|c|}
\hline Legume/strain & Chlorophyll & Shoot weight ${ }^{b}$ & No. nodules per plant & Nodule weight ${ }^{b}$ \\
\hline \multicolumn{5}{|l|}{ S. flavescens } \\
\hline Control & $25.79 \pm 0.69 \mathrm{a}$ & $0.065 \pm 0.003 a$ & 0 & 0 \\
\hline Ensifer fredii $\mathrm{WT}$ & $35.25 \pm 1.02 b$ & $0.076 \pm 0.005 b$ & $8.57 \pm 1.13$ & $0.041 \pm 0.005$ \\
\hline E. fredii $\Delta$ nodC & $25.56 \pm 1.54 \mathrm{a}$ & $0.065 \pm 0.003 a$ & 0 & 0 \\
\hline E. fredii $\Delta$ nodE & $25.27 \pm 0.64 \mathrm{a}$ & $0.027 \pm 0.001 \mathrm{~d}$ & 0 & 0 \\
\hline E. fredii $\Delta$ nodM & $28.24 \pm 0.73 a$ & $0.045 \pm 0.002 c$ & 0 & 0 \\
\hline Rhizobium yanglingense WT & $35.62 \pm 1.24 \mathrm{~b}$ & $0.074 \pm 0.004 b$ & $5.12 \pm 0.45$ & $0.04 \pm 0.003$ \\
\hline$R$. yanglingense $\Delta$ nod $C$ & $29.87 \pm 1.45 a$ & $0.055 \pm 0.002 \mathrm{a}$ & 0 & 0 \\
\hline$R$. yanglingense $\Delta$ nodE & $26.35 \pm 0.87 \mathrm{a}$ & $0.070 \pm 0.003 b$ & 0 & 0 \\
\hline Mesorhizobium amorphae WT & $37.84 \pm 0.81 b$ & $0.038 \pm 0.001 b$ & $4.05 \pm 0.41$ & $0.012 \pm 0.001$ \\
\hline M. amorphae $\Delta$ nodC & $28.74 \pm 0.87 a$ & $0.026 \pm 0.001 \mathrm{a}$ & 0 & 0 \\
\hline M. amorphae $\Delta$ nodM & $32.26 \pm 0.74 b$ & $0.029 \pm 0.002 \mathrm{a}$ & 0 & 0 \\
\hline \multicolumn{5}{|l|}{ Caragana intermedia } \\
\hline Control & - & $0.066 \pm 0.005 \mathrm{a}$ & 0 & 0 \\
\hline R. yanglingense WT & - & $0.092 \pm 0.006 b$ & $10.06 \pm 1.37$ & $0.031 \pm 0.003$ \\
\hline$R$. yanglingense $\Delta$ nodC & - & $0.054 \pm 0.008 \mathrm{a}$ & 0 & 0 \\
\hline R. yanglingense $\Delta$ nodE & - & $0.068 \pm 0.004 a$ & 0 & 0 \\
\hline M. amorphae WT & - & $0.059 \pm 0.001 b$ & $10 \pm 0.91$ & $0.018 \pm 0.002$ \\
\hline M. amorphae $\Delta$ nodC & - & $0.049 \pm 0.003 a$ & 0 & 0 \\
\hline M. amorphae $\Delta$ nodM & - & $0.056 \pm 0.003 b$ & 0 & 0 \\
\hline \multicolumn{5}{|l|}{ Glycine max } \\
\hline Control & $30.58 \pm 0.91 \mathrm{a}$ & $0.30 \pm 0.02 \mathrm{a}$ & 0 & 0 \\
\hline E. fredii WT & $36.27 \pm 0.78 b$ & $0.41 \pm 0.03 b$ & $7.12 \pm 0.74$ & $0.098 \pm 0.012$ \\
\hline E. fredii $\Delta$ nodC & $31.72 \pm 0.56 a$ & $0.30 \pm 0.03 a$ & 0 & 0 \\
\hline E. fredii $\Delta$ nodE & $23.19 \pm 0.70 \mathrm{a}$ & $0.53 \pm 0.03 a$ & 0 & 0 \\
\hline E. fredii $\Delta$ nodM & $27.35 \pm 0.78 \mathrm{a}$ & $0.55 \pm 0.02 \mathrm{a}$ & 0 & 0 \\
\hline
\end{tabular}

${ }^{a}$ WT $=$ wild type. Values and mean \pm standard deviation are shown. Different letters indicate significant difference based on Duncan's $t$ test $(P=0.05)$. - , no data available because the leaf is too small to be determined.

${ }^{\mathrm{b}}$ Weight was measured as grams per plant.

Table 3. Nodulation phenotype of lipochitooligosaccharide-decorated gene mutants and $\operatorname{Tn} 5$ mutants on Sophora flavescens and original hosts ${ }^{\mathrm{a}}$

\begin{tabular}{|c|c|c|c|c|}
\hline Legume/strain & Chlorophyll & Shoot weight & No. nodules per plant & Fresh nodule weight \\
\hline \multicolumn{5}{|l|}{ S. flavescens } \\
\hline Control & $26.96 \pm 0.78 \mathrm{a}$ & $0.029 \pm 0.002 \mathrm{a}$ & 0 & 0 \\
\hline E. fredii $\mathrm{WT}$ & $38.93 \pm 0.91 b$ & $0.060 \pm 0.003 \mathrm{c}$ & $14.33 \pm 1.28 \mathrm{a}$ & $0.017 \pm 0.002 \mathrm{a}$ \\
\hline E. fredii $\Delta$ nodS & $38.35 \pm 0.90 b$ & $0.040 \pm 0.001 b$ & $12.31 \pm 1.19 \mathrm{a}$ & $0.020 \pm 0.001 \mathrm{a}$ \\
\hline E. fredii $\Omega$ noel & $28.35 \pm 0.57 \mathrm{a}$ & $0.058 \pm 0.002 \mathrm{c}$ & $14.00 \pm 0.88 \mathrm{a}$ & $0.040 \pm 0.003 \mathrm{a}$ \\
\hline E. fredii $\Omega$ noeI $\Delta$ nodZ & $27.52 \pm 0.57 \mathrm{a}$ & $0.052 \pm 0.002 c$ & $14.00 \pm 0.88 \mathrm{a}$ & $0.051 \pm 0.002 b$ \\
\hline B. diazoefficiens $\mathrm{WT}$ & $30.55 \pm 0.40 \mathrm{~b}$ & $0.059 \pm 0.001 b$ & 0 & 0 \\
\hline B. diazoefficiens $\Omega$ noeI & $27.03 \pm 0.39 \mathrm{a}$ & $0.057 \pm 0.001 b$ & 0 & 0 \\
\hline B. diazoefficiens $\mathrm{Tn}-21$ & $28.73 \pm 4.24 \mathrm{a}$ & $0.035 \pm 0.012 \mathrm{a}$ & 1 to $11^{\mathrm{b}}$ & ND \\
\hline R. etli WT & $38.11 \pm 1.16 b$ & $0.039 \pm 0.002 b$ & $11.76 \pm 0.99 \mathrm{a}$ & $0.016 \pm 0.002 \mathrm{a}$ \\
\hline R. etli $\Delta \operatorname{nod} S$ & $37.30 \pm 0.71 b$ & $0.033 \pm 0.001 \mathrm{a}$ & $10.00 \pm 0.65 \mathrm{a}$ & $0.019 \pm 0.001 \mathrm{a}$ \\
\hline Mesorhizobium huakuii WT & $35.42 \pm 1.17 \mathrm{~b}$ & $0.039 \pm 0.002 b$ & $19.50 \pm 1.36 \mathrm{a}$ & $0.018 \pm 0.001 \mathrm{a}$ \\
\hline M. huakuii $\Delta$ nodH & $36.23 \pm 0.86 b$ & $0.034 \pm 0.002 b$ & $10.83 \pm 1.38 \mathrm{~b}$ & $0.013 \pm 0.001 \mathrm{a}$ \\
\hline \multicolumn{5}{|l|}{ Glycine max } \\
\hline Control & $26.84 \pm 0.59 \mathrm{a}$ & $0.403 \pm 0.020 \mathrm{a}$ & 0 & 0 \\
\hline E. fredii WT & $42.14 \pm 0.34 c$ & $0.648 \pm 0.032 \mathrm{~d}$ & $16.68 \pm 0.76 b$ & $0.179 \pm 0.007 \mathrm{a}$ \\
\hline E. fredii $\Delta$ nodS & $36.41 \pm 0.26 b$ & $0.502 \pm 0.020 \mathrm{bc}$ & $19.50 \pm 0.92 c$ & $0.217 \pm 0.008 b$ \\
\hline E. fredii $\Omega$ noeI & $40.94 \pm 0.44 c$ & $0.610 \pm 0.035 \mathrm{~cd}$ & $9.66 \pm 0.49 \mathrm{a}$ & $0.154 \pm 0.006 \mathrm{a}$ \\
\hline E. fredii $\Omega$ noeI $\Delta$ nodZ & $42.08 \pm 0.38 \mathrm{c}$ & $0.504 \pm 0.034 \mathrm{~b}$ & $10.90 \pm 0.53 \mathrm{a}$ & $0.160 \pm 0.006 \mathrm{a}$ \\
\hline B. diazoefficiens $\mathrm{WT}$ & $43.80 \pm 0.55 b$ & $0.652 \pm 0.032 b$ & $12.64 \pm 1.03 \mathrm{a}$ & $0.131 \pm 0.004 \mathrm{a}$ \\
\hline B. diazoefficiens $\Omega$ noeI & $28.10 \pm 0.93 a$ & $0.556 \pm 0.023 a$ & $16.55 \pm 1.33 b$ & $0.096 \pm 0.007 b$ \\
\hline \multicolumn{5}{|l|}{ Phaseolus vulgaris } \\
\hline Control & $24.33 \pm 1.65 \mathrm{a}$ & $0.348 \pm 0.035 \mathrm{a}$ & 0 & 0 \\
\hline R. etli WT & $36.76 \pm 0.60 b$ & $0.400 \pm 0.025 b$ & $56.50 \pm 3.71 \mathrm{a}$ & $0.143 \pm 0.015 a$ \\
\hline R. etli $\Delta$ nodS & $32.96 \pm 1.46 \mathrm{~b}$ & $0.425 \pm 0.026 b$ & $63.00 \pm 5.49 \mathrm{a}$ & $0.188 \pm 0.018 \mathrm{a}$ \\
\hline \multicolumn{5}{|l|}{ Astragalus sinicus } \\
\hline Control & ND & $0.0050 \pm 0.0002 \mathrm{a}$ & 0 & 0 \\
\hline M. huakuii WT & ND & $0.0066 \pm 0.0002 b$ & $4.37 \pm 0.34 \mathrm{a}$ & $0.0025 \pm 0.0002 \mathrm{a}$ \\
\hline M. huakuii $\Delta$ nodH & ND & $0.0058 \pm 0.0002 b$ & $3.22 \pm 0.52 \mathrm{a}$ & $0.0029 \pm 0.0002 \mathrm{a}$ \\
\hline
\end{tabular}

a Weights are given in grams per plant. Values are mean \pm standard deviation. Different letters indicate significant difference based on Duncan's $t$ test, $(P=$ $0.05)$. ND = not determined.

$\mathrm{b}$ The range of nodule numbers per plant is shown. 
in those inoculated with the WT strain (Table 3). The nodulation phenotype did not differ significantly between S. flavescens plants inoculated with the $M$. huakuii nodH mutant and those inoculated with its WT strain, but there were significantly fewer nodules on roots of $S$. flavescens infected by the mutant (Table 3). The noeI insertion mutant of $B$. diazoefficiens was able to nodulate $G$. max but not $S$. flavescens. The leaf chlorophyll content, shoot dry weight, number of nodules, and fresh weight of nodules were significantly lower in $G$. max plants inoculated with the $B$. diazoefficiens noeI mutant than in those inoculated with the WT strain. The noeI mutant of E. fredii was able to nodulate both $G$. max and S. flavescens; the leaf chlorophyll content was significantly lower in $S$. flavescens and the number of nodules was significantly lower in G. max infected by the $E$. fredii noeI mutant than in their respective counterparts inoculated with the WT strain of $E$. fredii (Table 3 ).

The double mutant ( $\triangle$ nodZSnoeI) of $E$. fredii was still able to nodulate $S$. flavescens and $G$. $\max$ but produced significantly fewer nodules and led to a significantly lower leaf chlorophyll content in G. max than did the WT strain of E. fredii (Table 3). The shoot dry weight and the fresh weight of nodules were slightly reduced in G. max infected with the double mutant, compared with G. max infected with the WT strain. However, in S. flavescens, the fresh weight of nodules was significantly greater and the leaf chlorophyll content was significantly less in plants inoculated with the double mutant than in those infected with the WT strain (Table 3).

\section{LCOs of WT and mutant $E$. fredii strains.}

The high-pressure liquid chromatography (HPLC) profiles

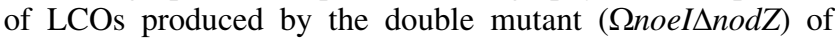
E. fredii and the WT E. fredii, the mass spectrometry (MS) ion fragments showing the characteristic structures of LCOs produced by the WT $\left(1,416.72\right.$ for NodSf-V [C ${ }_{18: 1}$, MeFuc], 1,213.64 for NodSf-IV [ $\left.\mathrm{C}_{18: 1}, \mathrm{MeFuc}\right], 1,010.56$ for NodSf-III $\left.\left[\mathrm{C}_{18: 1}, \mathrm{MeFuc}\right]\right)$, and double mutant $(1,053.57$ for NodSf-IV $\left[\mathrm{C}_{18: 1}, \mathrm{H}\right], 850.49$ for NodSf-III $\left.\left[\mathrm{C}_{18: 1}, \mathrm{H}\right]\right)$, and the deduced structures of LCOs produced by the WT strain and the double mutant are shown in Supplementary Figures S2 and S3. The mutants produced fewer types of LCOs than did the WT $E$. fredii strain. The WT E. fredii strain produced 18 LCOs with methyl- and methyl-fucose groups at the $\mathrm{R}_{4}$ position, while the double mutant produced 10 nonmodified LCOs with no substituent groups at positions $\mathrm{R}_{1}$ to $\mathrm{R}_{4}$ (Supplementary Figs. $\mathrm{S} 4$ and S5). The three predominant LCOs produced by the WT strain CCBAU 45436 were numbers 2, 10, and 18, corresponding to NodSf-V $\left(\mathrm{C}_{18: 1}, \mathrm{MeFuc}\right)$, NodSf-IV $\left(\mathrm{C}_{18: 1}, \mathrm{MeFuc}\right)$, and NodSf-III $\left(\mathrm{C}_{18: 1}, \mathrm{MeFuc}\right)$, respectively. The other 15 components (numbered 1, 3 to 9, and 11 to 17) were minor LCOs. The two major LCOs produced by the $E$. fredii double mutant were numbers 6 and 10, corresponding to NodSf-IV $\left(\mathrm{C}_{18: 1}, \mathrm{H}\right)$ and NodSf-III $\left(\mathrm{C}_{18: 1}, \mathrm{H}\right)$, respectively, and the other eight LCOs (No. 1 to 5,7 to 9 ) were minor ones.

\section{Nodulation assays using GIcNAc as inducer.}

Since the basic LCO structure was sufficient to induce functional nodules on $S$. flavescens and $G$. max, this assay tested whether a smaller LCO structure could trigger nodulation of $S$. flavescens. When the precursor of LCOs (GlcNAc) was added to roots of $S$. flavescens, no nodules formed. G. max plants inoculated with GlcNAc alone or with the combination of GlcNAc and the nodC-deletion mutant of $E$. fredii also did not form nodules. The leaf chlorophyll content and shoot weight were similar in the plants inoculated with GlcNAc alone, those in the control, and those inoculated with the nodC mutant (data not shown). Previously, it was thought that the basic LCO structure was synthesized sequentially by chain elongation, followed by deacetylation and acylation, and finally the addition of chemical substituents (Jabbouri et al. 1995). However, a recent study provided new insights into order of LCO biosynthesis (Poinsot et al. 2016); that is, chain elongation, fucosylation, deacetylation, $\mathrm{N}$ methylation, carbamoylation, acylation, and then arabinosylation. Whatever the order and complexity of LCOs biosynthesis, it requires NodC to form polymerized GlcNAc to induce nodules at least. Therefore, it is reasonable that the precursor of LCOs was insufficient to induce nodule formation on legumes.

\section{Tn5 mutant libraries}

\section{of USDA110 and nodulation abilities of mutants.}

Next, we determined whether the highly specific nodulation of B. diazoefficiens on soybean could be modified by mutating certain genes. A library of 800,000 independent Tn5 insertion mutants of B. diazoefficiens was constructed. Of the $180 \mathrm{~S}$. flavescens plants inoculated with the Tn 5 mutants, 116 formed normal nodules, with a range of 1 to 11 nodules per plant (Table 3, Tn-21 for example). The chlorophyll and shoot weight of the nodulated plants were higher than those of the uninoculated control (Table 3). Reisolation and identification of bacteria from Tn5 mutant-induced nodules revealed that these isolates were resistant to kanamycin $(\mathrm{Km})$ $(50 \mu \mathrm{g} / \mathrm{ml})$ and trimethoprim (Tmp) $(10 \mu \mathrm{g} / \mathrm{ml})$. Next, polymerase chain reaction (PCR) amplification and sequencing analyses of the flanking sequence of the $\operatorname{Tn} 5$ insertion position revealed 14 B. diazoefficiens mutants with a single copy of the $\operatorname{Tn} 5$ insertion integrated into their genome. Three mutants (Tn-18, Tn-19, and Tn-22) had the Tn 5 insertion in the same gene, which encoded SH3 domain-containing protein. Two mutants were related to membrane proteins (Tn-4 and Tn-5), one was related to a magnesium transporter (Tn-28) and one was related to $\mathrm{NAD}(\mathrm{P}) \mathrm{H}$-quinone oxidoreductase (Tn-10). Four mutants had the Tn5 insertion in genes encoding NAD (FAD)-utilizing dehydrogenase (Tn-11), isovalerylCoA dehydrogenase (Tn-21), phosphoenolpyruvic acid synthetase (Tn-2), and cyclopropane-fatty-acyl-phospholipid synthetase (Tn-25). Two mutants were related to chemotaxis (Tn-9) and a flagellum hook protein (Tn-7). All these mutated genes were dispersed throughout the genome and none was organized in an operon with other genes. We did not detect polar effects of the Tn 5 insertion.

\section{DISCUSSION}

Although many aspects of the molecular dialog determining the symbiotic specificity between rhizobia and their hosts have been explained, the reasons for the wide variation in the rhizobial spectrum associated with different legume species are still unknown. In this study, we explored this mechanism from the rhizobial side, focusing on the roles of genes involved in the synthesis of LCO and its side-chain modifications in nodulation and host-specificity.

Rhizobia secrete NFs (in essence, LCOs) after induction by flavonoids released by the roots of legumes. The LCOs function as key signaling molecules and can be perceived by the NF receptor of the host plant to trigger a cascade response in the root hairs. It is thought that the recognition and specificity between a rhizobium and its host legume are related to the phylogeny of nod genes and the structure of LCOs, especially their side-chain modifications (Roche et al. 1991). Previously, it was reported that the promiscuous symbiotic relationship of the medicinal legume $S$. flavescens with diverse rhizobia in the classes Alphaproteobacteria and Betaproteobacteria was independent of nodC phylogeny (Jiao et al. 2015). In the present study, the promiscuously symbiotic feature of $S$. flavescens was further confirmed, since it was effectively nodulated by five rhizobial strains (E. fredii, $R$. yanglingense, M. amorphae, $R$. etli, and $M$. huakuii) harboring different types of nodC genes. The nodC mutants of the five rhizobial strains failed to nodulate $S$. flavescens, clearly demonstrating that NFs are essential for the promiscuous nodulation of $S$. flavescens. The failure of the NF monomer 
(GlcNAc) to complement the $E$. fredii nodC mutant to nodulate soybean and $S$. flavescens indicated that complete NFs are required to establish an effective symbiosis with both legumes.

In previous studies, a nodE mutant that produced only NFs containing a $\mathrm{C}_{18: 1}$ group failed to nodulate or poorly nodulated the hosts (Demont et al. 1993; Economou et al. 1994; Li et al. 2011; Spaink et al. 1991). Furthermore, the difference in host range between Rhizobium leguminosarum bvs. trifolii and viciae was shown to be determined by the overall hydrophobicity of the highly unsaturated fatty acyl moieties of LCOs rather than by a specific structural feature (Spaink et al. 1995). Another study reported that the NodE proteins of $R$. trifolii and $R$. leguminosarum were crucial factors in determining their host ranges (Spaink et al. 1989). Other reports indicated that mutation or increased copy number of nodE did not affect the nodulation phenotype of host legumes (Philip-Hollingsworth et al. 1995; Walker and Downie 2000).

A mutation in nodM was shown to quantitatively decrease the production of LCOs that were identical in structure (Spaink et al. 1991, 1992). Another nodM mutant led to the production of deformed root hairs and showed delayed nodulation on Medicago sativa (Baev et al. 1991). Although NodM is essential for bacteroid maturation (Baev et al. 1992), mutation of nodM in $R$. leguminosarum did not significantly affect nodulation (Surin and Downie 1988). In the present study, the nodE- and nodM-deleted mutant of $E$. fredii, the nodE-deleted mutant of $R$. yanglingense, and the nod $M$-deleted mutant of $M$. amorphae failed to nodulate $S$. flavescens and their original hosts. These results demonstrated that nodE and nodM are necessary for nodulation but are not related to the wide rhizobial spectrum of $S$. flavescens.

Modifications of LCOs at the reducing and nonreducing ends are believed to determine host specificity (López-Lara et al. 1996; Roche et al. 1991). In the present study, however, the deletion or mutation of the NF-decoration genes nodS, nodZ, noeI, and nodH did not affect the nodulation range, and the modified rhizobia could still nodulate their original hosts and $S$. flavescens. The nodulation efficiency and the plant-growth phenotypes were altered in the mutant-inoculated plants, as compared with WT-inoculated plants (Table 3). These results indicated that nodS, nodZ, noel, and nodH are not directly involved in the promiscuous nodulation of S. flavescens. Some interesting phenomena were revealed by comparing nodulation phenotypes between the gene mutants and the WT strains.

In previous studies, the nodS gene was shown to be involved in $\mathrm{N}$ methylation and required for nodulation of Leucaena leucocephala (Jabbouri et al. 1995; Lewin et al. 1990). Furthermore, the transfer of nodSU from NGR234 to E. fredii USDA257 conferred the ability to nodulate Leucaena spp. (Krishnan et al. 1992). Similarly, introduction of the Rhizobium tropici CIAT899 nodS into $R$. etli, a strain that only nodulates $P$. vulgaris, extended its host range to L. leucocephala (Waelkens et al. 1995). However, the nodSU from $B$. diazoefficiens was unable to complement a $\operatorname{nod} S$ mutant of NGR234 (Göttfert et al. 1990). In many E. fredii strains, such as USDA257 and HH103, either this gene or its nod box are nonfunctional, consistent with the lack of $N$-methylation of NFs in both strains (Bec-Ferté et al. 1994; Krishnan et al. 1992; Vinardell et al. 2015). This is also the reason why these strains cannot nodulate Leucaena spp. Furthermore, NodS in E. fredii lacks the conserved domain showing similarity to $S$-adenosyl-methioninedependent methyltransferases (Göttfert et al. 1990; Waelkens et al. 1995). This may explain why the NFs produced by $E$. fredii USDA257 and HH103 are unmethylated. In this study, the NFs secreted by $E$. fredii CCBAU 45436 and its double mutant were unmethylated at the nonreducing end $\left(\mathrm{R}_{2}=\mathrm{H}\right)$. Therefore, we compared the sequences of the E. fredii CCBAU 45436 nodS gene to those of USDA257 and HH103 and other methylated NF-producing strains. The NodS amino acid sequences were similar among E. fredii 45436, USDA257, and HH103, all lacking the conserved domain, while the NodSs of $R$. tropici and NGR234 contained the conserved domain (Supplementary Fig. S6).
Although the number of nodules and fresh weight of nodules were significantly increased on G. max inoculated with nodS mutants of E. fredii, the shoot dry weight was significantly decreased (Table 3). Therefore, we checked whether the transcription of nodC was affected by the deletion of nodS. The quantitative PCR analyses showed that there was no significant difference in the nodC transcript levels between the nodS mutant and WT of E. fredii (Supplementary Fig. S7). Previous studies reported methylation at the nonreducing end of LCOs in $R$. etli strains CE-3 and CFN42 (Cárdenas et al. 1995; D'Haeze and Holsters 2002; Villalobos et al. 1994). In the present study, S. flavescens infected by the nodSmutant of $R$. etli showed significantly reduced shoot dry weight (Table 3). Other nodulation phenotypes were similar to those of plants inoculated with WT. Therefore, regardless of whether their NFs are methylated or not, these two strains retained the ability to nodulate the promiscuous legume $S$. flavescens.

$\operatorname{nodZ}$, nodH, and noeI are involved in fucosylation (QuesadaVincens et al. 1997; Stacey et al. 1994), sulfation (Faucher et al. 1988), and methylation (Perret et al. 2000; Sanjuan et al. 1992), respectively, at the reducing end of LCOs and have been reported to determine host-specificity (Faucher et al. 1988). nodZ was shown to be essential for the formation of normal infection threads and nodulation of Lotus spp. by Mesorhizobium loti R7A (Rodpothong et al. 2009). A mutation in nodZ of Bradyrhizobium japonicum led to defective nodulation of siratro (Macroptilium atropurpureum) (López-Lara et al. 1996). Transfer of nodZ to R. leguminosarum bv. viciae extended its host range (López-Lara et al. 1996). However, mutation of noeL (involved in fucosylation of NFs) and noeI did not abolish the ability of S. fredii $\mathrm{HH} 103$ and Rhizobium sp. strain NGR234 to nodulate several host legumes (Jabbouri et al. 1998; Madinabeitia et al. 2002). In this study, mutants of nodZ and noeI in E. fredii and nodH in M. huakuii retained their ability to nodulate their hosts of origin (soybean or A. sinicus, respectively) and $S$. flavescens (Table 3 ). The B. diazoefficiens mutant with an insertion in noeI retained its ability to nodulate soybean but still could not nodulate $S$. flavescens (Table 3).

To identify the functions of mutated nod genes and the structures of NFs synthesized by the mutants, we extracted the LCOs from the E. fredii WT and double mutant ( $\Omega$ noeI $\Delta$ nodZ). The structures of LCOs showed that nodS did not function in the WT or the double mutant. The double mutant produced a minimal LCO comprising the oligosaccharide with a fatty acyl group at the nonreducing end, and it was still able to nodulate $S$. flavescens and soybean. Therefore, the minimal LCO was sufficient for nodulation on soybean and $S$. flavescens. This may be one reason why these two legumes can be nodulated by a wide range of rhizobia harboring different types of LCOs. In another study, nondecorated NFs were shown to be sufficient for nodulation of soybean (Lamrabet et al. 1999).

Previous studies have shown that $B$. diazoefficiens cannot nodulate $S$. flavescens, although the WT B. diazoefficiens produces NFs structurally identical to those of E. fredii (Bec-Ferté et al. 1994; Duzan et al. 2006; Sanjuan et al. 1992). These findings confirmed that nodulation is not only dependent on NFs but also on other bacterial molecular signals, such as surface polysaccharides and effector proteins delivered into host cells via the T3SS (Downie 2010; López-Baena et al. 2016). Other studies have reported that flavonoids induce the expression of numerous genes (not only nod genes) that are likely to be involved in transport and other molecular signals (Acosta-Jurado et al. 2016; Ardissone et al. 2011; Lang et al. 2008; Pérez-Montaño et al. 2016). In this study, we found that there may be some negative control mechanism in WT B. diazoefficiens to prevent it from nodulating $S$. flavescens. The formation of normal nodules on $S$. flavescens by $14 \mathrm{Tn} 5$ mutants suggested that genes involved in negative regulation had been disrupted. The identification of these negative regulatory genes in $B$. diazoefficiens will provide new insights into the host-specificity functions of nodulation 
( $h s n$ ) genes. Therefore, promiscuity is dependent not only on the host but, also, on the rhizobia. Different rhizobia produce different sets of symbiotic signals that can either promote or prevent nodulation, depending on the host legume. These findings also explain the results of a previous study in which gene mutations expanded the host range (Brewin et al. 1980). In fact, the host range of E. fredii has been shown to be broader than that of $B$. diazoefficiens (Pérez-Montaño et al. 2016; Perret et al. 2000). B. diazoefficiens may produce a set of signals that are sufficient for its host plant but prevent nodulation on other legumes.

\section{Conclusions and remarks.}

The results of this study showed that the promiscuous nodulation of $S$. flavescens with diverse rhizobia depends on its ability to recognize various NFs with or without side-chain decorations. Mutations of genes involved in NF decoration (nodH, nodZ, noeI, and nodS) did not affect the nodulation specificity but altered the nodule phenotypes and the nitrogen-fixation efficiency to some degree. Mutagenesis by $\operatorname{Tn} 5$ insertions in the genome of $B$. diazoefficiens extended its host range to $S$. flavescens, indicating the existence of negative regulatory genes in some rhizobia that limit their host range. Further analyses of the specific biochemical functions of the negative regulators involved in determining the host range and in nodule development are ongoing.

\section{MATERIALS AND METHODS}

\section{Bacterial strains and growth conditions.}

Table 1 lists the bacterial strains and plasmids used in this work. The strains E. fredii CCBAU 45436 (Zhang et al. 2011) and B. diazoefficiens USDA110 ${ }^{\mathrm{T}}$ (Delamuta et al. 2013) were isolated from soybean $(G$. max). R. etli $\mathrm{CFN} 42$ was isolated from $P$. vulgaris (Segovia et al. 1993). $R$. yanglingense CCBAU 01603 and M. amorphae CCBAU 01583 were isolated from $C$. intermedia $(\mathrm{Li}$ et al. 2012), and $M$. huakuii 7653R was isolated from A. sinicus (Wang et al. 2014). Except for USDA 110, the other five strains were able to nodulate $S$. flavescens as well as their hosts of origin (Jiao et al. 2015). All the rhizobial strains were cultured at $28^{\circ} \mathrm{C}$ on tryptone-yeast (TY) medium (Beringer 1974) or yeast extract mannitol (YEM) medium (Vincent 1970) and were stored at $-80^{\circ} \mathrm{C}$ in $20 \%$ (wt/vol) glycerol. Escherichia coli DH5 $\alpha$ was grown at $37^{\circ} \mathrm{C}$ in Luria-Bertani medium (Miller 1972) supplemented with one or more antibiotics at the following concentrations (per milliliter), as required for different rhizobial strains: $30 \mu \mathrm{g}$ of nalidixic acid (NA), $10 \mu \mathrm{g}$ of Tmp, $50 \mu \mathrm{g}$ of $\mathrm{Km}, 30 \mu \mathrm{g}$ of gentamicin $(\mathrm{Gm})$, and $10 \mu \mathrm{g}$ of tetracycline (Tet). To extract NFs, the WT strain E. fredii CCBAU45436 and its $\Omega$ noeI $\Delta$ nod $Z$ double mutant were cultured in minimal liquid vitamin-containing (Vm) medium (Vincent 1970) supplemented with monosodium glutamate ( $1 \mathrm{~g} /$ liter), monosodium succinate ( $2 \mathrm{~g} /$ /iter), and D-mannitol (3 g/liter).

\section{Selection and mutation of nodulation genes.}

To analyze the function of NFs in the promiscuous nodulation of $S$. flavescens, the common nodulation genes nodC, nodE, and nodM and the strain-specific nodulation genes nodH, nodS, nodZ, and noeI were mutated in different strains. nod $C$ encodes $N$-acetylglucosamine transferase, which is involved in the synthesis of the LCO skeleton. The deletion of nodC completely blocks LCO synthesis. Therefore, the nodC genes were deleted from the five S. flavescens-nodulating strains (Table 1) to determine whether LCO was essential in the molecular dialogue between $S$. flavescens and rhizobia from different crossing nodulation groups. nod $M$ encodes D-glucosamine synthetase (Baev et al. 1992) and nodE encodes $\beta$-ketoacyl synthase (Demont et al. 1993). In a previous study, mutants of nodM and nodE genes in some rhizobia failed to nodulate or poorly nodulated their hosts (Economou et al. 1994). Therefore, the nodM and nodE genes in strains of E. fredii, M. amorphae, and
$R$. yanglingense were also mutated to determine their functions in nodulation and their possible roles in the synthesis of the complete LCO structure. By searching the literature and blasting gene sequences against the whole genome of the rhizobial strains, genes involved in LCO decoration, which is related to the host specificity of some strains, were identified for mutation by deletion or insertion. These genes included nodS, noeI, and nodZ in E. fredii, noeI in $B$. diazoefficiens, nodE in $R$. yanglingense, nodS in $R$. etli, and nodH in $M$. huakuii (Table 1).

\section{Nodulation tests with WT and mutant rhizobial strains.}

To confirm the nodulation ability of the rhizobial strains (Table 1) on both $S$. flavescens and their host of origin, seeds of S. flavescens (hard episperm softened using concentrated sulfuric acid for 20 min), G. max cv. Jidou 17, C. intermedia, P. vulgaris, and A. sinicus were surface-sterilized in $3 \%$ (vol/vol) $\mathrm{NaClO}$ solution and were then germinated on $0.7 \%$ water-agar plates, as described elsewhere (Jiao et al. 2015). Seedlings were transferred to a Leonard jar assembly containing sterile vermiculite moistened with a low-nitrogen plant nutrient solution (Vincent 1970). Each treatment consisted of 20 plants, with one plant per jar. Each plant was inoculated with $1 \mathrm{ml}$ of rhizobial culture (optical density at $600 \mathrm{~nm}$ $\left[\mathrm{OD}_{600}\right.$ ] concentration of 0.2 , diluted with $0.8 \% \mathrm{NaCl}$ ) or $8 \mathrm{mg}$ of GlcNAc per liter. This nodulation test was repeated three times. Plants were grown in a greenhouse under a 16-h light and 8-h dark photoperiod $\left(25^{\circ} \mathrm{C}\right.$ days, $16^{\circ} \mathrm{C}$ nights) and were harvested and checked from 26 to 45 days postinoculation (dpi). Several biological characteristics were compared between plants inoculated with WT and mutant strains. Leaf chlorophyll concentrations were determined using a SPAD-502 meter (Konica Minolta, Osaka, Japan) (Ling et al. 2011). Plant shoots were dried at $65^{\circ} \mathrm{C}$ for 5 days and, then, were weighed. The number of root nodules per plant was counted.

\section{Construction of nodulation gene mutants.}

To test the roles of nodulation genes in the promiscuous nodulation of $S$. flavescens, the common nodulation genes nodC (Kamst et al. 1997), nodE (Demont et al. 1993), and nodM (Baev et al. 1992), and the NF-modification genes $\operatorname{nod} S, \operatorname{nodH}, \operatorname{nodZ}$, and noeI, which may be related to host specificity, were chosen as the mutation targets. To delete $\operatorname{nod} C(\operatorname{\Delta nodC})$, we designed deletion primers corresponding to each strain (Supplementary Table S2). The mutant gene fragment was generated with a PCR-based protocol and was then cloned and introduced into the WT strain by transconjugation. Taking the strain E. fredii CCBAU 45436 as an example, DNA fragments containing the upstream amino-terminal coding region and the downstream carboxyl-terminal coding region of nodC were amplified by PCR, using the primer pairs 4CupL/4CupR and 4CdownL/4CdownR, respectively. These two fragments were digested with $E c o \mathrm{RI} / K p n \mathrm{I}$ and BsiWI/AgeI and were then cloned into the restriction sites of pCM351 digested using the same enzymes. The recombined plasmid was introduced into the recipient rhizobium (strain CCBAU 45436) with pRK2013 $\left(\mathrm{Km}^{\mathrm{r}}\right)$ as a helper plasmid by triparental conjugation. Recombined strains were selected on TY agar plates containing $\mathrm{Gm}$ and NA, each at $30 \mu \mathrm{g} / \mathrm{ml}$. The double-crossover mutants formed by gene replacement were selected by their antibiotic resistance phenotype (Gm- and NA-resistant but Tet-sensitive). Genetic modifications in the constructed mutants were verified by PCR amplification and DNA sequencing. The deletion mutants of nod genes in E. fredii ( $\Delta$ nodE, $\Delta$ nodM, and $\Delta$ nodS), R. yanglingense ( $\triangle$ nodC and $\triangle$ nodE), M. amorphae ( $\Delta$ nodC and $\Delta$ nodM), M. huakuii ( $\Delta$ nod $C$ and $\Delta \operatorname{nod} H)$, and $R$. etli ( $\Delta \operatorname{nod} C$ and $\Delta$ nodS) (Table 1) were constructed in the same way.

To mutate the noeI genes ( $\Omega$ noel) in E. fredii and B. diazoefficiens, we used the insertion plasmid pVO155 (Table 1). A 726-bp fragment of the noeI gene of E. fredii was obtained by PCR, using the primers 4 EproL and 4EproR. Then, the PCR product 


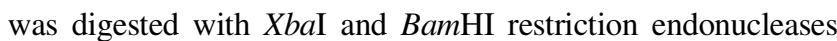
and was ligated into pVO155 digested with the same enzymes. The recombined plasmid was introduced into recipient cells, with pRK2013 $\left(\mathrm{Km}^{\mathrm{r}}\right)$ as a helper plasmid, by triparental conjugation. Mutated cells were selected on TY agar plates containing $\mathrm{Km}$ at $50 \mu \mathrm{g} / \mathrm{ml}$ and NA at $30 \mu \mathrm{g} / \mathrm{ml}$. Gene insertion mutants were verified by their antibiotic resistance phenotype (Km- and NA-resistant). Genetic modification in the single crossover was verified by PCR amplification and DNA sequencing.

The double mutant ( $\Omega$ noeI $\Delta$ nodZ) of $E$. fredii was generated as follows. DNA fragments containing the upstream aminoterminal coding region and the downstream carboxyl-terminal coding region of nodZ were obtained by PCR, using the primer pairs 4ZupL/4ZupR and 4ZdownL/4ZdownR, respectively. These two fragments were digested with EcoRI/KpnI and ApaI/AgeI and were cloned into the EcoRI/KpnI and ApaI/AgeI restriction sites of pCM351. The resulting plasmid was trans-

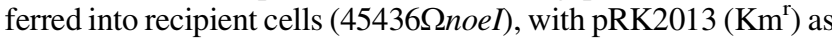
a helper plasmid, by triparental conjugation. The mutant was confirmed by PCR amplification and sequencing as described above.

\section{Construction of Tn5 mutagenesis library of $B$. diazoefficiens.}

To test if host specificity was negatively controlled by certain genes in B. diazoefficiens USDA 110, a strain obtained from a soybean nodule that failed to nodulate $S$. flavescens, $\operatorname{Tn} 5$ transposon mutations were introduced into $B$. diazoefficiens by conjugative transfer of the plasmid pRL1063a (Wolk et al. 1991) with the helper plasmid pRK2013. Briefly, $300 \mu \mathrm{l}$ of donor cells and $200 \mu \mathrm{l}$ of helper-recipient cells were mixed, and the suspension was spread onto TY agar plates. The plates were incubated at $28^{\circ} \mathrm{C}$ for 4 days, and the bacteria grown on the plates were then suspended and vortexed in $1 \mathrm{ml}$ of sterilized $0.8 \% \mathrm{NaCl}$ as the original suspension, before being diluted to $10^{-1}$. Both the original and the diluted suspensions (0.1-ml aliquots) were spread onto TY plates containing Tmp and $\mathrm{Km}$ to select for the transconjugants containing Tn5. After incubation at $28^{\circ} \mathrm{C}$ for 10 days, colonies growing on the plates were collected and were washed with sterilized $0.8 \% \mathrm{NaCl}$, were resuspended to $\mathrm{OD}_{600}=0.3$, and were then inoculated onto $S$. flavescens seedlings ( $1 \mathrm{ml}$ per plant). The plants were grown in Leonard jars and were cultured in the greenhouse as described above. A total of 200 S. flavescens plants were grown.

\section{Identification and sequence analysis of Tn5-inserted genes.}

In this experiment, we investigated which genes limited the host spectrum of $B$. diazoefficiens. Root nodules of $S$. flavescens inoculated by the $B$. diazoefficiens $\mathrm{Tn} 5$ mutants were harvested at $40 \mathrm{dpi}$. The nodules were sequentially rinsed in $95 \%$ ethanol for $30 \mathrm{~s}, 2.5 \% \mathrm{NaClO}$ for $5 \mathrm{~min}$, and then eight times with sterilized water, before being crushed in a sterilized tube. Then, $5 \mu \mathrm{L}$ crude extract was inoculated onto TY plates containing Tmp and Km. Total DNA from B. diazoefficiens:: Tn5 insertion derivatives grown in TY liquid was extracted using the Promega Wizard Genomic DNA Purification Kit (Promega, Madison, WI, USA) and used as the template for DNA amplification by PCR with the primers $415 \mathrm{~L} / 415 \mathrm{R}$ (inner primer of $\mathrm{Tn} 5$ transposon) and $820 \mathrm{~L} / 415 \mathrm{R}$ (external primer of $\operatorname{Tn} 5$ transposon) to verify successful insertion (i.e., amplification positive by primer pair $415 \mathrm{~L} / 415 \mathrm{R}$ and negative by primer pair $820 \mathrm{~L} / 820 \mathrm{R})$. The DNA extracted from mutants was digested with EcoRI and nucleic acid was precipitated using a nucleic acid precipitation kit (Dr. GenTLE precipitation carrier) from TaKaRa (Dalian, China) and was then self-ligated and transferred into E. coli competent cells by heat-shock $\left(42^{\circ} \mathrm{C}, 90 \mathrm{~s}\right)$. Positive clones resistant to $\mathrm{Km}$ were chosen for sequencing the transposon genome junction region, using the specific primer PM. The nucleotide sequence of each Tn5-inserted fragment was identified by comparison with sequences in the GenBank database via Blastn analysis at the National Center for Biotechnology Information.

\section{Extraction and analysis of NFs.}

These analyses explored the relationship between rhizobial NF structure and nodulation on S. flavescens. The E. fredii WT strain and its $\Omega$ noeI $\Delta$ nodZ double mutant were separately cultured in 9 lieters of $\mathrm{Vm}$ medium, as described above, to prepare sufficient material to extract NFs. Genistein $(15 \mu \mathrm{M})$ was added to the culture when cell density reached $0.2\left(\mathrm{OD}_{600}\right)$. When the $\mathrm{OD}_{600}$ reached 1.6 to 1.8 , NFs were extracted from the supernatant by partitioning with $n$-butanol, as described previously (Bonaldi et al. 2011). Crude extracts were purified using a HPLC system (Waters Acquity H Class UPLC; Waters Corp., Milford, MA, U.S.A.) equipped with a semipreparative ODS2 C18 reverse-phase column (Waters symmetry C18, 4.6× $150 \mathrm{~mm}, 5 \mu \mathrm{m})$. The chromatographic separation was performed using a binary gradient of water and acetonitrile. The elution profile was a linear increase from $10 \%$ (vol/vol) acetonitrile to $30 \%$ ( $\mathrm{vol} / \mathrm{vol}$ ) acetonitrile over $8 \mathrm{~min}$, followed by a 4-min linear increase from $30 \%$ (vol/vol) acetonitrile to $100 \%$ ( vol/vol) acetonitrile, and finally, an isocratic gradient of acetonitrile for $5 \mathrm{~min}$. The system was reconditioned with $10 \%$ ( $\mathrm{vol} / \mathrm{vol}$ ) acetonitrile for $5 \mathrm{~min}$ (flow rate, $1 \mathrm{ml} / \mathrm{min}$ ). The injection volume was $50 \mu \mathrm{l}$. The eluent of the HPLC column was monitored at $206 \mathrm{~nm}$. The elution range from 8 to $12 \mathrm{~min}$ comprising the fractions containing NFs was evaporated to dryness, was redissolved in $100 \mu \mathrm{l}$ of $50 \%$ ( $\mathrm{vol} / \mathrm{vol}$ ) acetonitrile, and was separated by HPLC-MS (Thermo Q Exactive Focus; Thermo Fisher Scientific, Waltham, MA, U.S.A.) on a C18 reversed-phase column (Waters Acquity UPLC BEH C18, $2.1 \times$ $100 \mathrm{~mm}, 1.7 \mu \mathrm{m})$. The mobile phase consisted of acetonitrile and water containing $0.1 \%$ formic acid (linear gradient from $5 \%$ acetonitrile to $90 \%$ ( $\mathrm{vol} / \mathrm{vol}$ ) acetonitrile over $10 \mathrm{~min}$, followed by an isocratic gradient of acetonitrile for $3 \mathrm{~min}$ ). The system was reconditioned with $5 \%(\mathrm{vol} / \mathrm{vol})$ acetonitrile for $3 \mathrm{~min}$ (flow rate, $0.3 \mathrm{ml} / \mathrm{min}$ ). The injection volume was $10 \mu \mathrm{l}$. The MS was set to the following optimized tune parameters: sheath gas flow rate, $30 \mathrm{psi}$; auxiliary gas flow rate, $10 \mathrm{psi}$; sweep gas flow rate, 5 psi; spray voltage, $3.5 \mathrm{KV}$; capillary temperature, $320^{\circ} \mathrm{C}$; s-lens RF level, 55; and auxiliary gas heater temperature, $350^{\circ} \mathrm{C}$. Spectra were recorded in the positive mode and peaks were detected in the expected range (800 to $1,600 \mathrm{~m} / \mathrm{z})$.

\section{Activity assays of $\boldsymbol{N}$-acetylglucosamine.}

To assess if the NF precursor $N$-acetylglucosamine (GlcNAc) had bioactivity in nodulation, $1 \mathrm{ml}$ of GlcNAc $(8 \mathrm{mg} / \mathrm{liter})$ was added to the root rhizosphere of $S$. flavescens and G. max cv. Jidou 17, individually or in combination with E. fredii WT strain $(1 \mathrm{ml})$ or its $\Delta$ nodC mutant $(1 \mathrm{ml})$. At $40 \mathrm{dpi}$, the number and fresh weight of nodules, shoot dry weight, and leaf chlorophyll concentrations were measured and compared.

\section{Quantitative reverse transcription (RT)-PCR.}

To measure the transcript level of nodC in E. fredii WT and its nodS mutant, RT-PCR experiments were performed using the primer pair $\mathrm{rt}-\mathrm{CF} / \mathrm{rt}-\mathrm{CR}$. The $16 \mathrm{~S}$ rRNA of E. fredii was used as an internal control to normalize the gene transcript level (primer pair rt-16S-F/rt-16S-R). For RNA isolation, E. fredii WT and its nodS mutant were each cultured in liquid YEM medium at $28^{\circ} \mathrm{C}$. Genistein $(1 \mu \mathrm{M})$ was added to the culture when cell density reached $0.2\left(\mathrm{OD}_{600}\right)$ and cells were cultured for another $6 \mathrm{~h}$. Cell cultures without genistein were used as the control. Total RNA was isolated, using the StarSpin bacterial RNA kit (GenStar Beijing) according to the manufacturer's instructions. This RNA 
(DNA-free) was reverse-transcribed into cDNA using a StarScript II First-strand cdna synthesis kit (GenStar). Quantitative PCR was performed using a LightCycler 480 (Roche, Switzerland) with the following conditions: initial denaturation, $95^{\circ} \mathrm{C}$ for $10 \mathrm{~min} ; 40$ cycles of $15 \mathrm{~s}$ at $95^{\circ} \mathrm{C}, 60 \mathrm{~s}$ at $60^{\circ} \mathrm{C}$. The fold changes of three biological samples with three technical replicates in each condition were calculated as described by Pfaffl et al. (2002).

\section{ACKNOWLEDGMENTS}

This work was financially supported by the National Natural Science Foundation of China (31770039), the National Basic Research Program of China (973 program 2015CB158300), and the Chinese Universities Scientific Fund (2017TC030). E. T. Wang was financially supported by the projects SIP 20130828 and 20120760 authorized by Instituto Politecnico Nacional, Mexico. The authors thank Y. G. Li for gifting seeds and rhizobium, J. Smith for editing a draft of the manuscript, and two anonymous reviewers whose constructive suggestions improved the manuscript.

\section{LITERATURE CITED}

Acosta-Jurado, S., Navarro-Gómez, P., Murdoch, Pdel. S., Crespo-Rivas, J. C., Jie, S., Cuesta-Berrio, L., Ruiz-Sainz, J. E., Rodríguez-Carvajal, M. A., and Vinardell, J. M. 2016. Exopolysaccharide production by Sinorhizobium fredii $\mathrm{HH} 103$ is repressed by genistein in a nodD1dependent manner. PLoS One 11:e0160499.

Ardissone, S., Noel, K. D., Klement, M., Broughton, W. J., and Deakin, W. J. 2011. Synthesis of the flavonoid-induced lipopolysaccharide of Rhizobium Sp. strain NGR234 requires rhamnosyl transferases encoded by genes $r g p F$ and $w b g A$. Mol. Plant-Microbe Interact. 24:1513-1521.

Baev, N., Endre, G., Petrovics, G., Banfalvi, Z., and Kondorosi, A. 1991. Six nodulation genes of nod box locus 4 in Rhizobium meliloti are involved in nodulation signal production: $\operatorname{nod} M$ codes for D-glucosamine synthetase. Mol. Gen. Genet. 228:113-124.

Baev, N., Schultze, M., Barlier, I., Ha, D. C., Virelizier, H., Kondorosi, E., and Kondorosi, A. 1992. Rhizobium nodM and $\operatorname{nod} N$ genes are common nod genes: nodM encodes functions for efficiency of nod signal production and bacteroid maturation. J. Bacteriol. 174:7555-7565.

Bec-Ferté, M. P., Krishnan, H. B., Promé, D., Savagnac, A., Pueppke, S. G., and Promé, J. C. 1994. Structures of nodulation factors from the nitrogen-fixing soybean symbiont Rhizobium fredii USDA257. Biochemistry 33:11782-11788.

Beringer, J. E. 1974. $R$ factor transfer in Rhizobium leguminosarum. J. Gen. Microbiol. 84:188-198.

Bonaldi, K., Gargani, D., Prin, Y., Fardoux, J., Gully, D., Nouwen, N., Goormachtig, S., and Giraud, E. 2011. Nodulation of Aeschynomene afraspera and A. indica by photosynthetic Bradyrhizobium sp. strain ORS285: The nod-dependent versus the nod-independent symbiotic interaction. Mol. Plant-Microbe Interact. 24:1359-1371.

Brewin, N. J., Beringer, J. E., and Johnston, A. W. B. 1980. Plasmidmediated transfer of host-range specificity between two strains of Rhizobium leguminosaurm. J. Gen. Microbiol. 120:413-420.

Cárdenas, L., Domínguez, J., Quinto, C., López-Lara, I. M., Lugtenberg, B. J., Spaink, H. P., Rademaker, G. J., Haverkamp, J., and Thomas-Oates, J. E. 1995. Isolation, chemical structures and biological activity of the lipo-chitin oligosaccharide nodulation signals from Rhizobium etli. Plant Mol. Biol. 29:453-464.

D'Haeze, W., and Holsters, M. 2002. Nod factor structures, responses, and perception during initiation of nodule development. Glycobiology 12: 79R-105R.

Day, R. B., McAlvin, C. B., Loh, J. T., Denny, R. L., Wood, T. C., Young, N. D., and Stacey, G. 2000. Differential expression of two soybean apyrases, one of which is an early nodulin. Mol. Plant-Microbe Interact. 13:1053-1070.

Delamuta, J. R. M., Ribeiro, R. A., Ormeño-Orrillo, E., Melo, I. S., Martínez-Romero, E., and Hungria, M. 2013. Polyphasic evidence supporting the reclassification of Bradyrhizobium japonicum group Ia strains as Bradyrhizobium diazoefficiens sp. nov. Int. J. Syst. Evol. Microbiol. 63:3342-3351.

Demont, N., Debellé, F., Aurelle, H., Dénarié, J., and Promé, J. C. 1993. Role of the Rhizobium meliloti nodF and nodE genes in the biosynthesis of lipo-oligosaccharidic nodulation factors. J. Biol. Chem. 268 : 20134-20142.

diCenzo, G. C., Zamani, M., Milunovic, B., and Finan, T. M. 2016. Genomic resources for identification of the minimal $\mathrm{N}_{2}$-fixing symbiotic genome. Environ. Microbiol. 18:2534-2547.
Downie, J. A. 2010. The roles of extracellular proteins, polysaccharides and signals in the interactions of rhizobia with legume roots. FEMS Microbiol. Rev. 34:150-170

Duzan, H. M., Mabood, F., Souleimanov, A., and Smith, D. L. 2006. Nod $\mathrm{Bj}-\mathrm{V}\left(\mathrm{C}_{18: 1}\right.$, MeFuc) production by Bradyrhizobium japonicum (USDA110, 532C) at suboptimal growth temperatures. J. Plant Physiol. 163:107-111

Economou, A., Davies, A. E., Johnston, A. W. B., and Downie, J. A. 1994 The Rhizobium Ieguminosarum biovar viciae nodO gene can enable a nodE mutant of Rhizobium leguminosarum biovar trifolii to nodulate vetch. Microbiology 140:2341-2347.

Faucher, C., Maillet, F., Vasse, J., Rosenberg, C., van Brussel, A. A., Truchet, G., and Dénarié, J. 1988. Rhizobium meliloti host range nodH gene determines production of an alfalfa-specific extracellular signal. J. Bacteriol. 170:5489-5499.

Figurski, D. H., and Helinski, D. R. 1979. Replication of an origincontaining derivative of plasmid RK2 dependent on a plasmid function provided in trans. Proc. Natl. Acad. Sci. U.S.A. 76:1648-1652.

Giraud, E., Moulin, L., Vallenet, D., Barbe, V., Cytryn, E., Avarre, J.-C., Jaubert, M., Simon, D., Cartieaux, F., Prin, Y., Bena, G., Hannibal, L., Fardoux, J., Kojadinovic, M., Vuillet, L., Lajus, A., Cruveiller, S., Rouy, Z., Mangenot, S., Segurens, B., Dossat, C., Franck, W. L., Chang, W.-S., Saunders, E., Bruce, D., Richardson, P., Normand, P., Dreyfus, B., Pignol, D., Stacey, G., Emerich, D., Verméglio, A., Médigue, C., and Sadowsky, M. 2007. Legumes symbioses: Absence of Nod genes in photosynthetic bradyrhizobia. Science 316:1307-1312.

Göttfert, M., Hitz, S., and Hennecke, H. 1990. Identification of nodS and nodU, two inducible genes inserted between the Bradyrhizobium japonicum nodYABC and nodIJ genes. Mol. Plant-Microbe Interact. 3: 308-316.

Jabbouri, S., Fellay, R., Talmont, F., Kamalaprija, P., Burger, U., Relić, B., Promé, J. C., and Broughton, W. J. 1995. Involvement of nodS in $\mathrm{N}$ methylation and nodU in 6-O-carbamoylation of Rhizobium sp. NGR234 nod factors. J. Biol. Chem. 270:22968-22973.

Jabbouri, S., Relić, B., Hanin, M., Kamalaprija, P., Burger, U., Promé, D., Promé, J. C., and Broughton, W. J. 1998. nolO and noeI (HsnIII) of Rhizobium sp. NGR234 are involved in 3-O-carbamoylation and 2-Omethylation of Nod factors. J. Biol. Chem. 273:12047-12055.

Jiao, Y. S., Liu, Y. H., Yan, H., Wang, E. T., Tian, C. F., Chen, W. X., Guo, B. L., and Chen, W. F. 2015. Rhizobial diversity and nodulation characteristics of the extremely promiscuous legume Sophora flavescens. Mol. Plant-Microbe Interact. 28:1338-1352.

Kamst, E., Pilling, J., Raamsdonk, L. M., Lugtenberg, B. J., and Spaink, H. P. 1997. Rhizobium nodulation protein NodC is an important determinant of chitin oligosaccharide chain length in Nod factor biosynthesis. J. Bacteriol. 179:2103-2108.

Krishnan, H. B., Lewin, A., Fellay, R., Broughton, W. J., and Pueppke, S. G. 1992. Differential expression of nodS accounts for the varied abilities of Rhizobium fredii USDA257 and Rhizobium sp. strain NGR234 to nodulate Leucaena spp. Mol. Microbiol. 6:3321-3330.

Lamrabet, Y., Bellogín, R. A., Cubo, T., Espuny, R., Gil, A., Krishnan, H. B., Megias, M., Ollero, F. J., Pueppke, S. G., Ruiz-Sainz, J. E., Spaink, H. P., Tejero-Mateo, P., Thomas-Oates, J., and Vinardell, J. M. 1999. Mutation in GDP-fucose synthesis genes of Sinorhizobium fredii alters Nod factors and significantly decreases competitiveness to nodulate soybeans. Mol. Plant-Microbe Interact. 12:207-217.

Lang, K., Lindemann, A., Hauser, F., and Göttfert, M. 2008. The genistein stimulon of Bradyrhizobium japonicum. Mol. Genet. Genomics 279 203-211.

Lewin, A., Cervantes, E., Chee-Hoong, W., and Broughton, W. J. 1990. nodSU, two new nod genes of the broad host range Rhizobium strain NGR234 encode host-specific nodulation of the tropical tree Leucaena leucocephala. Mol. Plant-Microbe Interact. 3:317-326.

Li, M., Li, Y., Chen, W. F., Sui, X. H., Li, Y., Jr., Li, Y., Wang, E. T., and Chen, W. X. 2012. Genetic diversity, community structure and distribution of rhizobia in the root nodules of Caragana spp. from arid and semi-arid alkaline deserts, in the north of China. Syst. Appl. Microbiol. 35:239-245.

Li, R., Knox, M. R., Edwards, A., Hogg, B., Ellis, T. H., Wei, G., and Downie, J. A. 2011. Natural variation in host-specific nodulation of pea is associated with a haplotype of the SYM37 LysM-type receptor-like kinase. Mol. Plant-Microbe Interact. 24:1396-1403.

Ling, Q., Huang, W., and Jarvis, P. 2011. Use of a SPAD-502 meter to measure leaf chlorophyll concentration in Arabidopsis thaliana. Photosynth. Res. 107:209-214

Long, S. R. 1989. Rhizobium-legume nodulation: Life together in the underground. Cell 56:203-214.

Long, S. R. 1996. Rhizobium symbiosis: Nod factors in perspective. Plant Cell 8:1885-1898. 
Long, S. R. 2001. Genes and signals in the rhizobium-legume symbiosis. Plant Physiol. 125:69-72.

López-Baena, F. J., Ruiz-Sainz, J. E., Rodríguez-Carvajal, M. A., and Vinardell, J. M. 2016. Bacterial molecular signals in the Sinorhizobium fredii-soybean symbiosis. Int. J. Mol. Sci. 17:755.

López-Lara, I. M., Blok-Tip, L., Quinto, C., Garcia, M. L., Stacey, G. Bloemberg, G. V., Lamers, G. E. M., Lugtenberg, B. J. J., Thomas-Oates, J. E., and Spaink, H. P. 1996. NodZ of Bradyrhizobium extends the nodulation host range of Rhizobium by adding a fucosyl residue to nodulation signals. Mol. Microbiol. 21:397-408.

Madinabeitia, N., Bellogín, R. A., Buendía-Clavería, A. M., Camacho, M., Cubo, T., Espuny, M. R., Gil-Serrano, A. M., Lyra, M. C., Moussaid, A., Ollero, F. J., Soria-Díaz, M. E., Vinardell, J. M., Zeng, J., and RuizSainz, J. E. 2002. Sinorhizobium fredii $\mathrm{HH} 103$ has a truncated nolO gene due to a -1 frameshift mutation that is conserved among other geographically distant $S$. fredii strains. Mol. Plant-Microbe Interact. 15:150-159.

Marx, C. J., and Lidstrom, M. E. 2002. Broad-host-range cre-lox system for antibiotic marker recycling in gram-negative bacteria. Biotechniques 33 : 1062-1067.

Marx, H., Minogue, C. E., Jayaraman, D., Richards, A. L., Kwiecien, N. W., Siahpirani, A. F., Rajasekar, S., Maeda, J., Garcia, K., Del ValleEchevarria, A. R., Volkening, J. D., Westphall, M. S., Roy, S., Sussman, M. R., Ané, J. M., and Coon, J. J. 2016. A proteomic atlas of the legume Medicago truncatula and its nitrogen-fixing endosymbiont Sinorhizobium meliloti. Nat. Biotechnol. 34:1198-1205.

Miller, J. H. 1972. Experiments in Molecular Genetics. Cold Spring Harbor Laboratory, Cold Spring Harbor, NY, U.S.A.

Oke, V., and Long, S. R. 1999. Bacterial genes induced within the nodule during the rhizobium-legume symbiosis. Mol. Microbiol. 32:837-849.

Pérez-Montaño, F., Jiménez-Guerrero, I., Acosta-Jurado, S., NavarroGómez, P., Ollero, F. J., Ruiz-Sainz, J. E., López-Baena, F. J., and Vinardell, J. M. 2016. A transcriptomic analysis of the effect of genistein on Sinorhizobium fredii $\mathrm{HH} 103$ reveals novel rhizobial genes putatively involved in symbiosis. Sci. Rep. 6:31592.

Perret, X., Staehelin, C., and Broughton, W. J. 2000. Molecular basis of symbiotic promiscuity. Microbiol. Mol. Biol. Rev. 64:180-201.

Pfaffl, M. W., Horgan, G. W., and Dempfle, L. 2002. Relative expression software tool (REST) for group-wise comparison and statistical analysis of relative expression results in real-time PCR. Nucleic Acids Res. 30:e36.

Philip-Hollingsworth, S., Orgambide, G. G., Bradford, J. J., Smith, D. K., Hollingsworth, R. I., and Dazzo, F. B. 1995. Mutation or increased copy number of $n o d E$ has no effect on the spectrum of chitolipooligosaccharide nod factors made by Rhizobium leguminosarum bv. trifolii. J. Biol. Chem. 270:20968-20977.

Poinsot, V., Crook, M. B., Erdn, S., Maillet, F., Bascaules, A., and Ané, J. M. 2016. New insights into Nod factor biosynthesis: Analyses of chitooligomers and lipo-chitooligomers of Rhizobium sp. IRBG74 mutants. Carbohydr. Res. 434:83-93.

Quesada-Vincens, D., Fellay, R., Nasim, T., Viprey, V., Burger, U., Prome', J. C., Broughton, W. J., and Jabbouri, S. 1997. Rhizobium sp. strain NGR234 NodZ protein is a fucosyltransferase. J. Bacteriol. 179: 5087-5093.

Roche, P., Debellé, F., Maillet, F., Lerouge, P., Faucher, C., Truchet, G., Dénarié, J., and Promé, J.-C. 1991. Molecular basis of symbiotic host specificity in Rhizobium meliloti: nodH and nodPQ genes encode the sulfation of lipo-oligosaccharide signals. Cell 67:1131-1143.

Rodpothong, P., Sullivan, J. T., Songsrirote, K., Sumpton, D., Cheung, K. W. J. T., Thomas-Oates, J., Radutoiu, S., Stougaard, J., and Ronson, C. W. 2009. Nodulation gene mutants of Mesorhizobium loti R7A-nodZ and nolL mutants have host-specific phenotypes on Lotus spp. Mol. Plant-Microbe Interact. 22:1546-1554.

Sanjuan, J., Carlson, R. W., Spaink, H. P., Bhat, U. R., Barbour, W. M., Glushka, J., and Stacey, G. 1992. A 2-O-methylfucose moiety is present in the lipo-oligosaccharide nodulation signal of Bradyrhizobium japonicum. Proc. Natl. Acad. Sci. U.S.A. 89:8789-8793.

Segovia, L., Young, J. P. W., and Martínez-Romero, E. 1993. Reclassification of American Rhizobium leguminosarum biovar phaseoli type I strains as Rhizobium etli sp. nov. Int. J. Syst. Bacteriol. 43:374-377.
Spaink, H. P., Aarts, A., Stacey, G., Bloemberg, G. V., Lugtenberg, B. J., and Kennedy, E. P. 1992. Detection and separation of Rhizobium and Bradyrhizobium Nod metabolites using thin-layer chromatography. Mol. Plant-Microbe Interact. 5:72-80.

Spaink, H. P., Bloemberg, G. V., Van Brussel, A. A. N., Lugtenberg, B. J. J., Van der Drift, K. M. G. M., Haverkamp, J., and Thomas-Oates, J. E. 1995. Host specificity of Rhizobium leguminosarum is determined by the hydrophobicity of the highly unsaturated fatty acyl moieties of nodulation fators. Mol. Plant-Microbe Interact. 8:155-164.

Spaink, H. P., Sheeley, D. M., van Brussel, A. A. N., Glushka, J., York, W. S., Tak, T., Geiger, O., Kennedy, E. P., Reinhold, V. N., and Lugtenberg, B. J. 1991. A novel highly unsaturated fatty acid moiety of lipo-oligosaccharide signals determines host specificity of Rhizobium. Nature 354:125-130.

Spaink, H. P., Weinman, J., Djordjevic, M. A., Wijffelman, C. A., Okker, R. J. H., and Lugtenberg, B. J. J. 1989. Genetic analysis and cellular localization of the Rhizobium host specificity-determining NodE protein. EMBO J. 8:2811-2818.

Stacey, G., Luka, S., Sanjuan, J., Banfalvi, Z., Nieuwkoop, A. J., Chun, J. Y., Forsberg, L. S., and Carlson, R. 1994. nodZ, a unique host-specific nodulation gene, is involved in the fucosylation of the lipooligosaccharide nodulation signal of Bradyrhizobium japonicum. J. Bacteriol. 176: 620-633.

Stajković-Srbinović, O., De Meyer, S. E., Miličić, B., Delić, D., and Willems, A. 2012. Genetic diversity of rhizobia associated with alfalfa in Serbian soils. Biol. Fertil. Soils 48:531-545.

Surin, B. P., and Downie, J. A. 1988. Characterization of the Rhizobium leguminosarum genes nodLMN involved in efficient host-specific nodulation. Mol. Microbiol. 2:173-183.

Tian, C. F., Zhou, Y. J., Zhang, Y. M., Li, Q. Q., Zhang, Y. Z., Li, D. F., Wang, S., Wang, J., Gilbert, L. B., Li, Y. R., and Chen, W. X. 2012. Comparative genomics of rhizobia nodulating soybean suggests extensive recruitment of lineage-specific genes in adaptations. Proc. Natl. Acad. Sci. U.S.A. 109:8629-8634

Villalobos, M. A., Nava, N., Vázquez, M., and Quinto, C. 1994. Nucleotide sequence of the Rhizobium etli nodS gene. Gene 150:201-202.

Vinardell, J. M., Acosta-Jurado, S., Zehner, S., Göttfert, M., Becker, A., Baena, I., Blom, J., Crespo-Rivas, J. C., Goesmann, A., Jaenicke, S., Krol, E., McIntosh, M., Margaret, I., Pérez-Montaño, F., SchneikerBekel, S., Serranía, J., Szczepanowski, R., Buendía, A. M., Lloret, J., Bonilla, I., Pühler, A., Ruiz-Sainz, J. E., and Weidner, S. 2015. the Sinorhizobium fredii HH103 genome: A comparative analysis with $S$. fredii strains differing in their symbiotic behavior with soybean. Mol. Plant-Microbe Interact. 28:811-824.

Vincent, J. M. 1970. A manual for the practical study of root nodule bacteria. IBP Handbook No. 15. Blackwell Scientific, Oxford.

Waelkens, F., Voets, T., Vlassak, K., Vanderleyden, J., and van Rhijn, P. 1995. The nodS gene of Rhizobium tropici strain CIAT899 is necessary for nodulation on Phaseolus vulgaris and on Leucaena leucocephala. Mol. Plant-Microbe Interact. 8:147-154.

Walker, S. A., and Downie, J. A. 2000. Entry of Rhizobium leguminosarum bv.viciae into root hairs requires minimal Nod factor specificity, but subsequent infection thread growth requires nod $O$ or nodE. Mol. PlantMicrobe Interact. 13:754-762.

Wang, L., Cao, Y., Wang, E. T., Qiao, Y. J., Jiao, S., Liu, Z. S., Zhao, L., and Wei, G. H. 2016. Biodiversity and biogeography of rhizobia associated with common bean (Phaseolus vulgaris L.) in Shaanxi Province. Syst. Appl. Microbiol. 39:211-219.

Wang, S., Hao, B., Li, J., Gu, H., Peng, J., Xie, F., Zhao, X., Frech, C., Chen, N., Ma, B., and Li, Y. 2014. Whole-genome sequencing of Mesorhizobium huakuii 7653R provides molecular insights into host specificity and symbiosis island dynamics. BMC Genomics 15:440

Wolk, C. P., Cai, Y., and Panoff, J. M. 1991. Use of a transposon with luciferase as a reporter to identify environmentally responsive genes in a cyanobacterium. Proc. Natl. Acad. Sci. U.S.A. 88:5355-5359.

Zhang, Y. M., Li, Y., Jr., Chen, W. F., Wang, E. T., Tian, C. F., Li, Q. Q., Zhang, Y. Z., Sui, X. H., and Chen, W. X. 2011. Biodiversity and biogeography of rhizobia associated with soybean plants grown in the North China Plain. Appl. Environ. Microbiol. 77:6331-6342. 